\title{
BIM AND DATA STANDARD FOR EFFECTIVE INVESTMENT IN INFRASTRUCTURE
}

\author{
Josef Zak, Stanislav Vitasek \\ Czech Technical University in Prague, Czech Republic \\ josef.zak@fsv.cvut.cz, stanisla.vitasek@fsv.cvut.cz
}

\begin{abstract}
Building information modeling has been gaining its attention worldwide in the construction industry. Digitalization of construction projects and associated workflows generated demands for data standardization. However, systems and data interoperability in the construction sector is an obstacle. This article is focusing on description of the strategy and data standard utilized on large infrastructure assets. The data standard has been prepared by BIM expert group founded by the State Transport Infrastructure Fund and the Ministry of Transportation. The data standard has been prepared in cooperation with the large design companies and construction companies as well as software developers and distributors present in the Czech Republic. The Czech Republic forms, to some extent, single European market and these design and construction companies operate worldwide. Focused groups, data analysis and international and national standards search were used as the research methods to prepare the technical regulations and methodologies presented in this paper. From this point of view, the presented data standard has ambition to became a guideline for other countries. The data standard presented in this article is in accordance with generally known principles present in the PAS 1192 series and CEN standardization. It took two years of experts work and an uncountable number of stakeholders' meetings and associated discussions to develop this data standard that is going to be used across preparation, design, construction and maintenance of the infrastructure projects. The data standard is at this moment being implemented in software solutions that are used by engineers to tackle their needs in shared digital environments. It is expected that the data standard will serve as a base stone for construction digitalization and catalyze software utilization with associated efficiency in infrastructure projects.
\end{abstract}

Keywords: BIM, EIR, data standard, infrastructure, IFC.

\section{Introduction}

BIM (Building Information Modeling or Building Information Management) is a set of information modeling processes - creating, updating, and managing construction project data throughout its lifecycle to optimize it and achieve added value [1]. Nowadays, BIM utilization is primarily about changing the approach - it is a collaboration of all project participants in real time with same data/model and in a shared common data environment. With the information on spatial constraints other necessary information, such as material properties, prices, maintenance and repair requirements, can be assigned to individual building elements. At the same time, such a model can be effectively interconnected with time scheduling to create additional model dimensions [2]. It is a new and big challenge for all participants in the individual phases of the building life cycle. The link between the financing of the transport infrastructure and the use of the BIM method is very significant from the infrastructure financing agencies point of view. BIM brings a reduction in the lifetime cost of infrastructures and a significant increase in efficiency.

To support the construction industry the Ministry of Transport, through its established body State Fund for Transportation Infrastructure, has established expert groups that drafted and negotiated the standards prepared in cooperation with state agencies, large design companies and construction companies as well as software developers and distributors present in the Czech Republic. From the methodical point of view, this expert group has used mixed research methods, such as focused groups, interviews, data analysis and international and national standards search. Extreme effort has been put not only in drafting these methodologies and regulations, but as well in negotiating a multi-party consensus on these documents.

\section{Financing of transport infrastructure from SFTI in 2001-2018}

The financing of transport infrastructure in the Czech Republic is largely ensured by the budget of the State Fund for Transport Infrastructure (hereinafter referred to as "SFTI"), the activity of which is regulated by [3], as amended hereinafter referred as "SFTI Act"). The overview of the transport infrastructure financing from the SFDI budget from 2001 to 2018 (broken down by the transport mode, the contributions provided under the SFDI Act are listed separately) is shown in Figure 1 and it shows that in total 1128 billion CZK were spent. The following diagram shows the statistics of these 
financial resources analyzed from multiple sources over last 17years and merged in logical groups representing fields where these resources have been used.

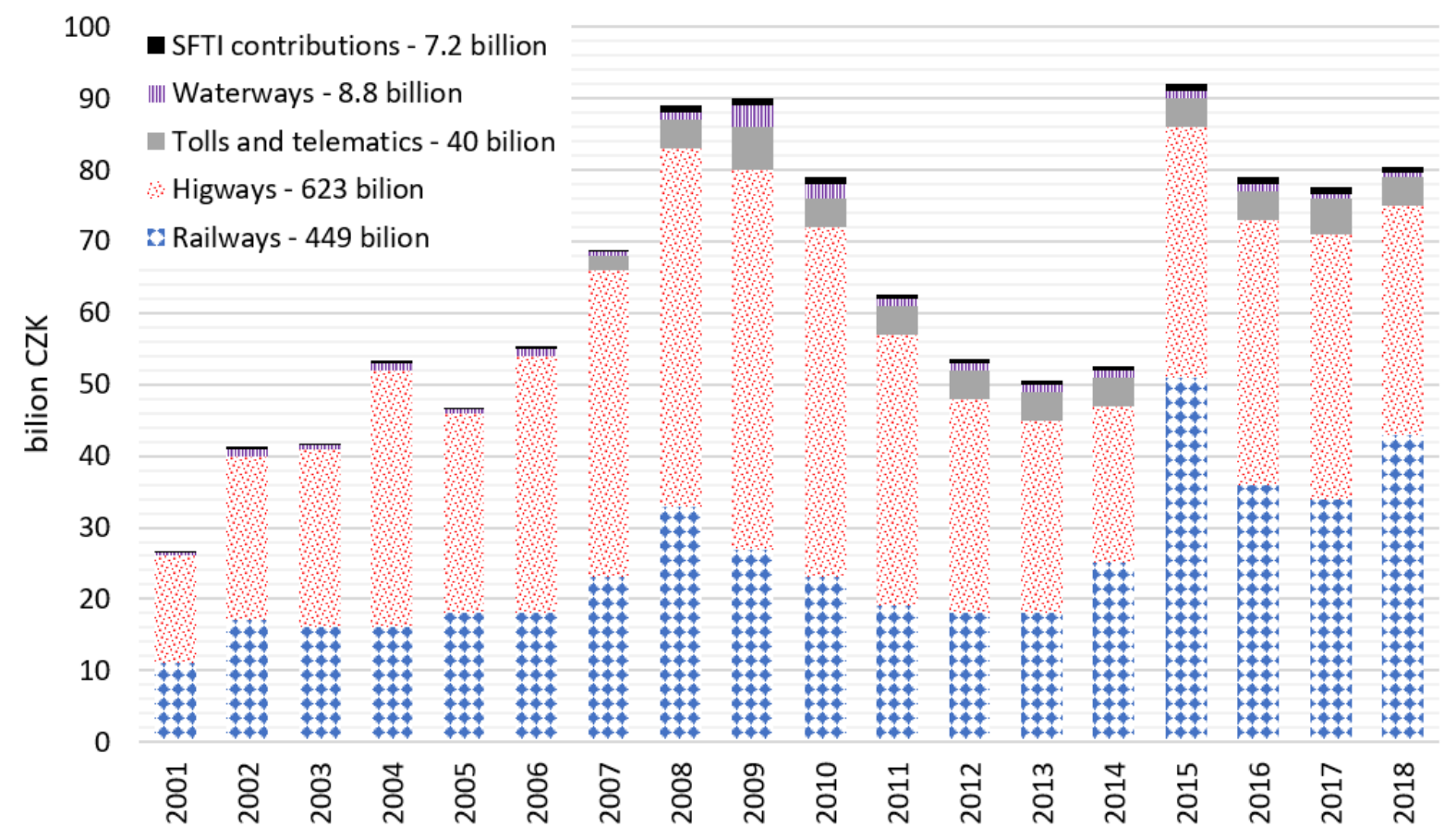

Fig. 1. Funds released to SFTI beneficiaries by type of infrastructure in 2001-2018 (in CZK billion) [4;5]

\section{Implementation of the BIM method - a part of the system of effective investment in infrastructure}

In addition to providing adequate resources for the needs of the transport infrastructure, the SFDI also has an important task to build and improve the system of effective spending of funds, which results from the Section 3 of the SFDI Act. In order to ensure this task and in view of the considerable amount of financial resources provided annually, the SFDI has prepared, in cooperation with the Ministry of Transport and sectoral investor organizations of the Road Motorways Directorate of the Czech Republic (RMD), Railways Infrastructure Administration (RIA) and the Directorate of Waterways of the Czech Republic, the standard control procedures implemented in accordance with the Act on Financial Control [3]. Continuously the system that uses todays well-established practices and tools is improved. One of the strategies to gradually built and improve the system to ensure efficient use of funds from the SFDI budget is the BIM implementation. Under the authority of the Ministry of Transport, the SFDI became the main coordinator of the implementation of the BIM method for transport constructions. In 2017, a Plan to Expand the Use of Digital Methods and Implementation of Building Information Modeling for Transport Infrastructure was prepared and approved [5]. In accordance with this plan, and in close cooperation with $R M D$ and RIA in particular, implementation of the plan was launched in three key areas:

- education;

- implementation of pilot projects to verify the benefits of the BIM method for transport structures;

- standardization of procedures through the preparation of technical regulations and methodologies.

\section{Preparation of technical regulations and methodologies for BIM}

Knowledge gained by targeted education and practical experience from the implementation of pilot projects of RMD and RIA are currently being used in the preparation of technical regulations and methodologies for standardization of the BIM method for infrastructure. The current task in the 
preparation of technical regulations for BIM is to ensure interoperability within the construction industry, which is motivated by public clients (RMD, RIA) demands.

\section{Interoperability and open data format}

Interoperability is a characteristic of a product or system, which interfaces are completely understood, to work with other products or systems, present or future, in either implementation or access, without any restrictions [6]. Most civil engineers will encounter this term only to a limited extent or not at all during their daily practice. And this is also one of the consequences of the current state in the construction industry.

In the construction industry there are a number of programs with customized features for users. These programs have proprietary data formats, these are data formats, which content and organization are known only to the authors of these data formats and related software products. Therefore, any use of the data requires the corresponding data format authoring software. The interoperability of these solutions is problematic. Without the interoperability of software solutions, construction cannot be collaborated, or collaboration on projects requires enormous costs associated with the large amount of data redesign between proprietary data formats.

An open format is a file format for storing digital data, defined by a published specification usually maintained by a standardization organization that can be used and implemented by anyone. Open formats are not encumbered with any restrictive copyright, patent, trademark, or other restriction and may therefore be used by anyone without any financial cost associated with their use. The open format can be implemented with both proprietary and free, and open software using its own software licenses used by each program user. Often these open data formats are used to convert between proprietary programs.

The cornerstone for creating collaborative conditions and efficient data transfer is to use open file formats. This file format within the construction industry is the internationally used IFC format, which is standardized under ISO [7]. The SFTI decided to utilize this open data format in the definition of its data standard.

\section{Data standard for infrastructure projects}

By using open data formats, access to these data is ensured. However, it is also necessary to define the content of these data, so that the open data formats contain data in a unified form created and edited as employer's information requirements. For this purpose, it is necessary to establish uniform rules for working with these data. In November 2018, the State Fund for Transport Infrastructure published a draft of the Building Infrastructure Information Modeling (BIM) Data Standard for Transport Infrastructure [8]. This document and its content are being briefly referred to as "the data standard".

Its purpose is to provide creators of data with adequate data for the creation of information models of transport infrastructure projects [9]. The data standard is a set of technical requirements and specifications, which has been prepared by the expert group. In this expert group key design companies and general contractors have nominated their representatives to work over two years on this specification. It is beyond this paper to publish the whole data standard. However, several principles are described in the following paragraphs.

\section{Data standard content}

The document specifies the basic requirements for the preparation of building information models and specifies the data creation rules for BIM, so that it can be used by the builder, designer, contractor, building component manufacturer, BIM library provider, etc. at all stages of building construction, execution and operation. It defines the details of models, building objects/operating files and individual elements, including their properties according to the project phases. It also specifies formats, units, scales, detail levels, individual file designations, model views, properties, color standards, and more.

The data standard is based on the open IFC data format, thus enabling the exchange of information between individual software platforms and at the same time extending the data specified in this data standard with additional data according to the user's needs. 
The data standard does not prescribe the way these data are created. This is the way in which users of the programs are used to work with and the choice of workflows for them.

Binding use of the data standard is recommended to be included in the contract terms for design and construction work.

The data standard scheme is shown in the following Figure 2.

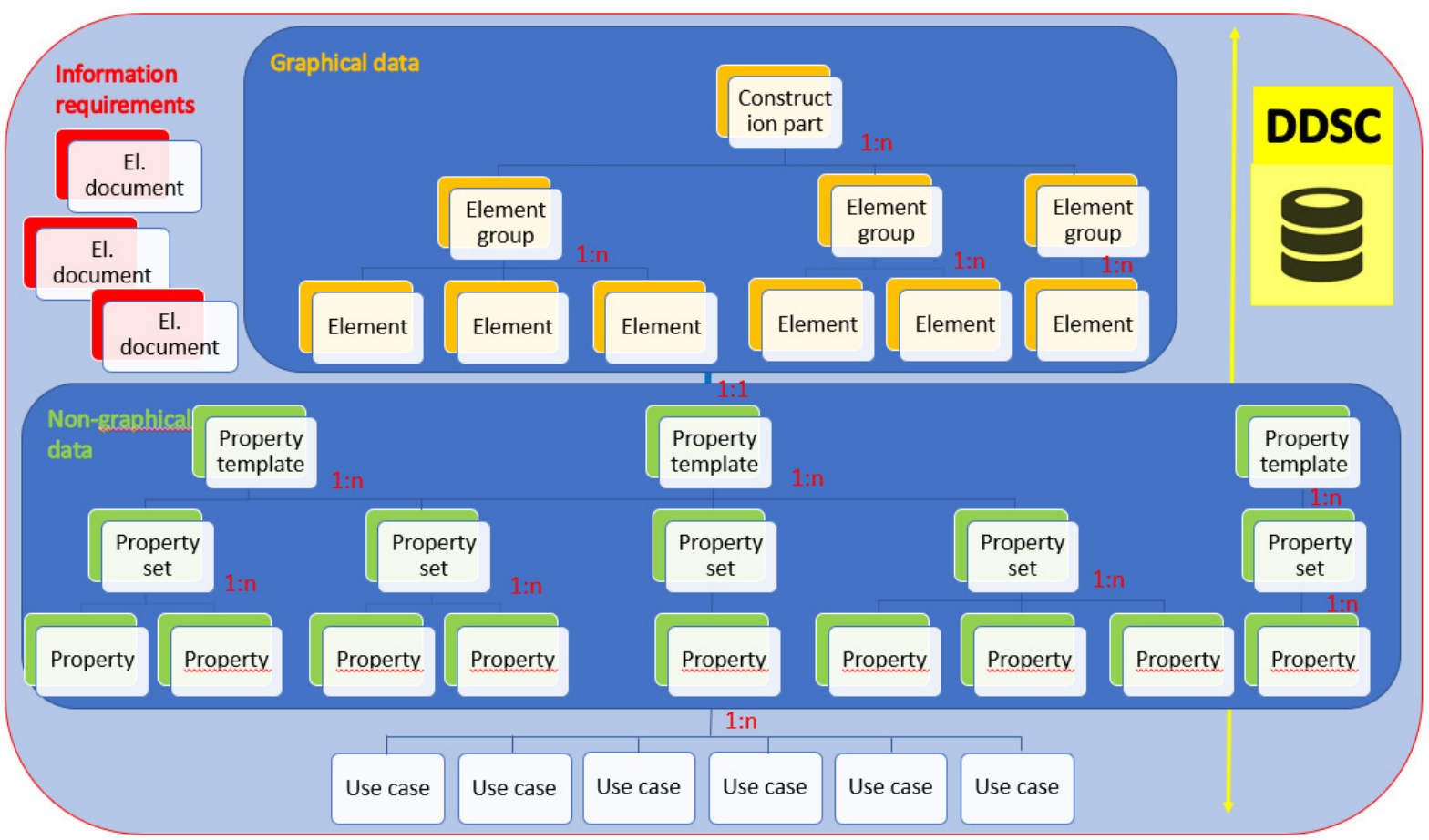

Fig. 2. Data standard scheme [8]

\section{Use cases}

Relevant data use cases were studied as part of the Building Information Modeling Usage Analysis (BIM) for infrastructure constructions [10]. Furthermore, the term "Use Case" is used for these uses. This analysis was processed in parallel with the data standard and information requirements specification. Thus, the data standard associates data into individual groups based on these Use Cases, thus creating a set of required information corresponding to the Use Case.

At the same time, the Use Case makes it easy for a user to define a data standard according to his or her requirements and needs for a project based on a unified methodology, architecture and structure that allows for expansion when needed.

The data standard sets out all standardized information in the model to be handled - for selected Uses Cases. The data standard cannot fully cover all conceivable uses of the BIM model and associated information. The data standard defines requirements for the data and associated Use Cases that have been identified in the analysis [10]. However, this does not mean that the data standard is limited to these uses.

\section{Use cases combinations}

In Appendices 1 and 2 - Data Standard, the "Property Set Indexes" are identified. The Property Set Indexes define the individual Data Uses and assign a set of properties to them. Such a principle allows the user to generate dynamic Information Delivery Manual (IDM). It comprehends the principle that some Use Cases contain data for other "simpler" Use Cases. At the same time, by combining several "simpler" Use Cases, data are obtained to such an extent that they correspond to "more complex" Use Cases.

In principle, it abides to that the data standard based information models can also be used for other needs beyond the currently defined data standard framework within the construction life cycle. 
The data standard allows for extensions based on user requirements. This is due to its architecture and the fact that it is based on the open neutral IFC file format.

\section{Data standard database for infrastructure construction}

As seen in Figure 1, the abbreviation DDSC stands for the Data standard database for infrastructure construction. The DDSC serves three main purposes.

- As part of the preparation of the data standard, it enabled the expert team members to cooperate on the definition of the standard - that is, the specification of which features of the individual elements are mandatory, when passing the BIM model, depending on the project phase and the required (expected) Use Cases.

- As part of the use of the data standard, it is intended to allow users to easily obtain a data standard specification for users based on the selected project phase and required Use Cases.

- Maintain complex data scheme (as seen in Figure 2) and allow modifications and maintenance of the content in systematic and error free environment.

The database and data standard structure are based on the following principles.

- Individual building elements (elements) are divided hierarchically into individual classes, with each class having one ancestor (a more general type of the element) and more descendants (more specific types of the element).

- Properties are not assigned directly to classes, but through so-called property sets.

- Multiple property sets can be assigned to a single element, and the element then contains properties from all assigned groups.

- A single property group can be assigned to multiple elements, so multiple elements can share properties and do not need to be re-defined.

- One property can be assigned to multiple property sets. As a result, one property in an element can be assigned multiple times through multiple property sets, but is contained only once.

- A property has its specified data type.

- Further details on DDSS are provided in the TAS Architecture Data Standard Architecture Concept.

\section{Properties}

Elements are assigned properties using property groups based on Use Cases. Property templates are made up of property sets. Property sets are made up of individual properties.

Properties are an information container that has defined property designations, data type, unit, value examples, value range, IFC designation, whether it is in the current IFC version, or a custom property set or property.

The properties form comprehensive requirements for non-geometric element information. In the case of custom property sets, the name of this property set/property is defined as ifcPropertySet, or ifcPropertyName.

\section{Construction products and constructions}

The data standard distinguishes elements into construction products and on site made constructions. The most noticeable difference is seen in the sets of properties, which, in the case of construction products, are based on the Declaration of Performance (DoP) under the [11] and their use in buildings and at the same time at the Ministry of Transport of the Czech Republic (MoT) and its internal technical policy. For the purpose of properties specification it was necessary to analyze the Declaration of Performance in accordance with the Construction Products Act and the MoT's Departmental Requirements. Subsequently, these property set requirements have been specified.

\section{Data formats}

The following specification has been selected to ensure mentioned interoperability within software platforms and at the same time maintain data in the data format of its origin. Thus, each and every model will be handed over in two formats: 
- IFC data format,

- the native CAD software format used to prepare the data (e.g. *.dwg, *.dgn, *.rvt,...) will be used.

At the same time, the following requirements have to be meat:

- data in both formats (IFC and native) match,

- the contractor (appointed party) is responsible for the correctness, content and integrity of the data in the transmitted format.

\section{Conclusions}

1. The availability of resources for transport infrastructure projects and the optimization of their effective use with the support of modern technologies, among which BIM undoubtedly belongs, are crucial for sustainable development and efficiency of infrastructure structures.

2. Digitalization of construction projects and associated workflows generates demands for data standardization. These demands have resulted from extensive work of key experts in the infrastructure sector in the Czech Republic. It took two years of the experts work and an uncountable number of stakeholders' meetings and associated discussions to develop this data standard that is going to be used across preparation, design, construction and maintenance of the infrastructure projects. This article describes the strategy and principles that are present in the data standard utilized on large infrastructure assets.

3. The data standard has been prepared by the BIM expert group funded by the State Transport Infrastructure Fund and the Ministry of Transportation in the Czech Republic. The data standard has been prepared in cooperation with the large design companies and construction companies as well as software developers and distributors present in the Czech Republic. Multiple consensuses have been found and even more compromises have been made to find a common approach that will be of benefit for the infrastructure construction sector.

4. The Czech Republic forms, with other countries, single European market, and design and construction companies present in the Czech Republic operate worldwide. From this point of view, the presented data standard has ambition to became a guideline for other countries.

5. The data standard is at this moment being implemented in software solutions that are used by engineers to tackle their needs in shared digital environments. National partners of international software developers (e.g. Autodesk, Bentley) together with national software developers (Pragoprojekt) are implementing this standard in their software solutions. It is expected that the data standard will serve as a base stone for construction digitalization and catalyze software utilization with associated efficiency in infrastructure projects.

\section{Acknowledgements}

This work was supported by the Grant Agency of the Czech Technical University in Prague, grant No. SGS19/017/OHK1/1T/11.

\section{References}

[1] Eastman C., Fischer D., Lafue G., Lividini J., Stoker D. Yessios C. "An Outline of the Building Description System." Carnegie-Mellon University, Pittsburgh, Institute of Phzsical Planning, 1974.

[2] Žák J., Vitásek S. "BIM Superior approach for infrastructure construction in the Czech Republic," Eng. Rural Dev. Proc. 17th Int. Sci. Conf., 2018, pp. 578-584.

[3] "Act No. 104/2000 Coll., On the State Fund for Transport Infrastructure." Goverment of Czech Republic, 2000.

[4] SFDI, "Annual Report on Activities and Financial Statements State Fund for Transport Infrastructure." State Fund for Transport Infrastructure, 2017, 2016, 2015, 2014, 2013, 2012, 2011, 2010, 2009, 2008, 2007, 2006, 2005, 2004, 2003, 2002, 2001-2018.

[5] Hořelica Z., Mertlová O., Vykydal I., Žák J. "Plan to Expand the Use of Digital Methods and Implement Building Information Modeling (BIM) for Transport Infrastructure (Building Information Modelling - BIM)" State Fund for Transportation Infrastructure, Aug-2017. 
[6] Eastman C., Teicholz P., Sacks R., Liston K. Wiley: BIM Handbook: A Guide to Building Information Modeling for Owners, Managers, Designers, Engineers and Contractors, 2nd Edition - Chuck Eastman, Paul Teicholz, Rafael Sacks, et al. 2011.

[7] ISO 16739, "Industry Foundation Classes (IFC) for data sharing in the construction and facility management industries." ISO, 2013.

[8] Zak J., Hejral J., Kafka O., Kratky M., Kutil L., Sirotek M. "Building Infrastructure Information Modeling (BIM) Data Standard for Transport Infrastructure." State Found for Transportation Infrastructure, 2018.

[9] Zak J., Macadam H. "Utilization of building information modeling in infrastructure's design and construction," in IOP Conf. Series: Materials Science and Engineering, 2017, pp. 1-6.

[10] Hejral J., Kafka O., Kratky M., Sirotek M., Zak J. "Analysis of the data use cases in Building Infroamtion Modeling for Infrastructure projects." State Found for stransportation Infrastructure, 2018.

[11] "Regulation (EU) No 305/2011." European Parliament and the Council, 2011. 